\title{
Conjunctival Melanoma with Ipsilateral, Non- Contiguous Eyelid Involvement: A Case Report and Comprehensive Review of the Literature
}

\author{
Kelsey A. Roelofs ${ }^{a} \quad$ Grigorios Mitsopoulos $^{b} \quad$ Victoria M.L. Cohen ${ }^{a}$ c \\ a Ocular Oncology Service, Moorfields Eye Hospital, London, UK; ${ }^{b}$ Ealing Hospital, London, UK; ' $\mathrm{NIHR}$ Biomedical \\ Research Centre, UCL Institute of Ophthalmology, London, UK
}

\section{Established Facts}

- Concurrent pigmentation of the ipsilateral eyelid can occur in up to $15 \%$ of cases of conjunctival melanoma.

- While conjunctival melanoma may extend into the eyelid in $1 \%$ of cases (AJCC cT3b), cases of noncontiguous conjunctival melanoma and eyelid melanoma are very rare with only 5 clearly documented reports in the English literature.

\section{Novel Insights}

- We report a rare case of conjunctival melanoma with non-contiguous eyelid melanoma and provide a comprehensive review of the literature.

- This case highlights the importance of long-term follow-up for patients diagnosed with conjunctival melanoma as some instances of secondary eyelid involvement occur several years following the initial diagnosis.

\section{Keywords}

Eyelid melanoma · Conjunctival melanoma · Primary acquired melanosis

\section{Abstract \\ While the majority of cases of conjunctival melanoma (CM) involve the bulbar conjunctiva, concurrent pigmentation of the ipsilateral eyelid can be seen in up to $15 \%$ of cases. Al- though extension of conjunctival melanoma into the eyelid (AJCC cT3b) occurs in 1\% of cases, non-contiguous lesions are very rare with only 5 clearly documented reports in the English literature. Several pathophysiological mechanisms have been proposed, including separate primary melano-}

mas, patchy involvement from primary acquired melanosis (which may be sine pigmento) and exfoliation of malignant tumour cells into the tear film. Herein we present a case of eyelid melanoma arising in a patient previously treated for $\mathrm{CM}$ at a non-contiguous site and provide a comprehensive review of the relevant literature.

(c) 2020 S. Karger AG, Basel

\section{Introduction}

Conjunctival melanoma $(\mathrm{CM})$ is a relatively rare malignancy, with a reported incidence of $0.2-0.5$ per million in Caucasian populations $[1,2]$. It most commonly arises from primary acquired melanosis (PAM) (56-74\%) but 

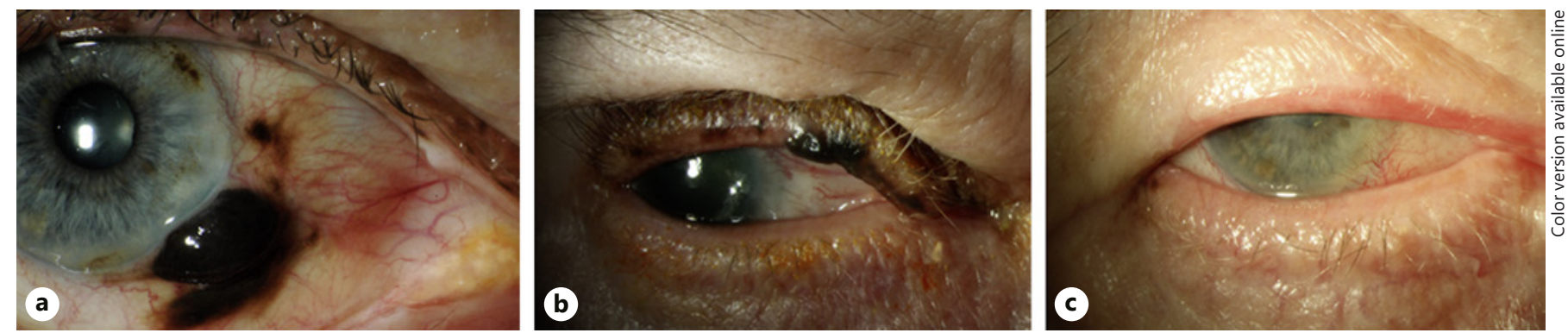

Fig. 1. a In May 2011, the patient presented with an elevated, pigmented lesion involving the inferonasal limbus. She was treated with excisional biopsy, double freeze-thaw cryotherapy and adjuvant strontium radiotherapy. b Three years later, a nodular thickening of the medial upper eyelid developed, with areas of flat patchy pigmentation along the mucocutaneous junction extend- ing laterally. Conjunctival scarring with no evidence of recurrent disease is appreciated at $4-5$ o'clock along the limbus corresponding to the area of previously treated conjunctival melanoma. c Following removal of the upper eyelid melanoma, a new area of cutaneous pigment was noted near the lateral canthus while the superior eyelid and nasal limbus remain free of recurrent disease. may also develop de novo (18-39\%) or from conjunctival naevi (4-26\%) [3-5]. Eyelid melanoma (EM) is a similarly rare entity, comprising $0.6 \%$ of eyelid malignancies [6] and only $0.19 \%$ of all cutaneous melanomas [7]. In contrast to conjunctival melanoma, cutaneous melanoma is rarely associated with the cutaneous counterpart of PAM, lentigo maligna. The lower lid is often involved (56-79\%) [8-10], and histological subtypes include superficial spreading melanoma (35-57\%), lentigo maligna melanoma (24-61\%) and nodular melanoma (19-59\%) [8-11].

Excisional biopsy, often with adjuvant cryotherapy, tends to be the mainstay of initial management for CM; however, local recurrence is common and affects up to $50-70 \%$ of patients at 10 years $[4,5,12]$. Moreover, $28 \%$ of patients will develop recurrence at a new site [13], and roughly one third will have more than one episode of recurrence [3]. Similarly, despite complete excision of the lesion on histopathology, nearly one quarter (21-24\%) of patients with EM go on to develop local recurrence $[8,11$, 14].

Although the majority of CMs involve the bulbar conjunctiva (92\%), 5-15\% can have concurrent eyelid pigmentation $[4,15]$. In a series of 17 patients with CM and ipsilateral eyelid pigmentation, Robertson et al. [15] found abnormal skin pigmentation to be a poor prognostic factor for metastasis and death. In this study, 3 patients were confirmed to have cutaneous involvement with melanoma at exenteration; however, in all cases CM arose in the fornix and was presumably contiguous with eyelid involvement [15]. Similarly, small series have also found lid margin involvement of EM to be a poor prognostic factor [16].
While extension of CM into the eyelid (AJCC cT3b) is seen in $1 \%$ of cases [5], lesions separated in time and/or location are very rare with only 5 clearly documented prior reports of non-contiguous melanomas involving the conjunctiva and ipsilateral eyelid skin [17-20]. Herein, we present a patient with CM who later developed ipsilateral cutaneous eyelid involvement at a non-contiguous location.

\section{Case Presentation}

In May 2011, a 73-year-old female was referred to the ocular oncology service at Moorfields Eye Hospital for assessment of a right pigmented conjunctival lesion involving the nasal limbus at $4-5$ o'clock (Fig. 1a). She had a history of PAM that had been noted approximately 3 years earlier. Excisional biopsy employing a no-touch technique with double freeze-thaw cryotherapy was undertaken. Review of histopathology confirmed CM arising from PAM with atypia. As the deep margins were positive, she subsequently underwent adjuvant strontium radiotherapy. Three years later, she developed an area of abnormal pigmentation involving the right upper eyelid margin and skin, and a full-thickness wedge resection of the upper eyelid was undertaken (Fig. 1b).

Review of histopathology showed invasive malignant melanoma with a partial covering of flattened conjunctival epithelium displaying features of melanosis with atypia. The adjacent cutaneous portion of the specimen was involved and showed features consistent with superficial spreading melanoma. Overall, the tumour measured $1 \mathrm{~mm}$ in thickness and $5 \mathrm{~mm}$ in horizontal dimension. Ulceration, lymphovascular and perineural infiltration were not identified. Mapping biopsies of the conjunctiva showed PAM with atypia while mapping biopsies of the surrounding skin showed melanoma in situ. As there was direct continuity between the surface melanocytic neoplasia and the invasive melanoma, this was not felt to represent an in-transit metastasis (Fig. 2). Following confirmation of complete exci- 
Fig. 2. a Haematoxylin and eosin stain showing invasive malignant melanoma at the eyelid margin. The invasive disease has a partial covering of flattened conjunctival epithelium showing features of melanosis with atypia while the adjacent more cutaneous portion was notable for a modest proliferation of atypical intraepithelial melanocytes consistent with superficial spreading melanoma. b Sampling of adjacent skin shows "overspill” of basal atypical melanocytic proliferation, in keeping with a diagnosis of lentigo maligna. c In 2017, excision of the lateral canthal cutaneous pigmentation revealed a basal proliferation of atypical melanocytes in a lentiginous pattern consistent with lentigo maligna. d Staining with Melan A highlights these melanocytes, which are more or less restricted to the basal part of the epithelium.

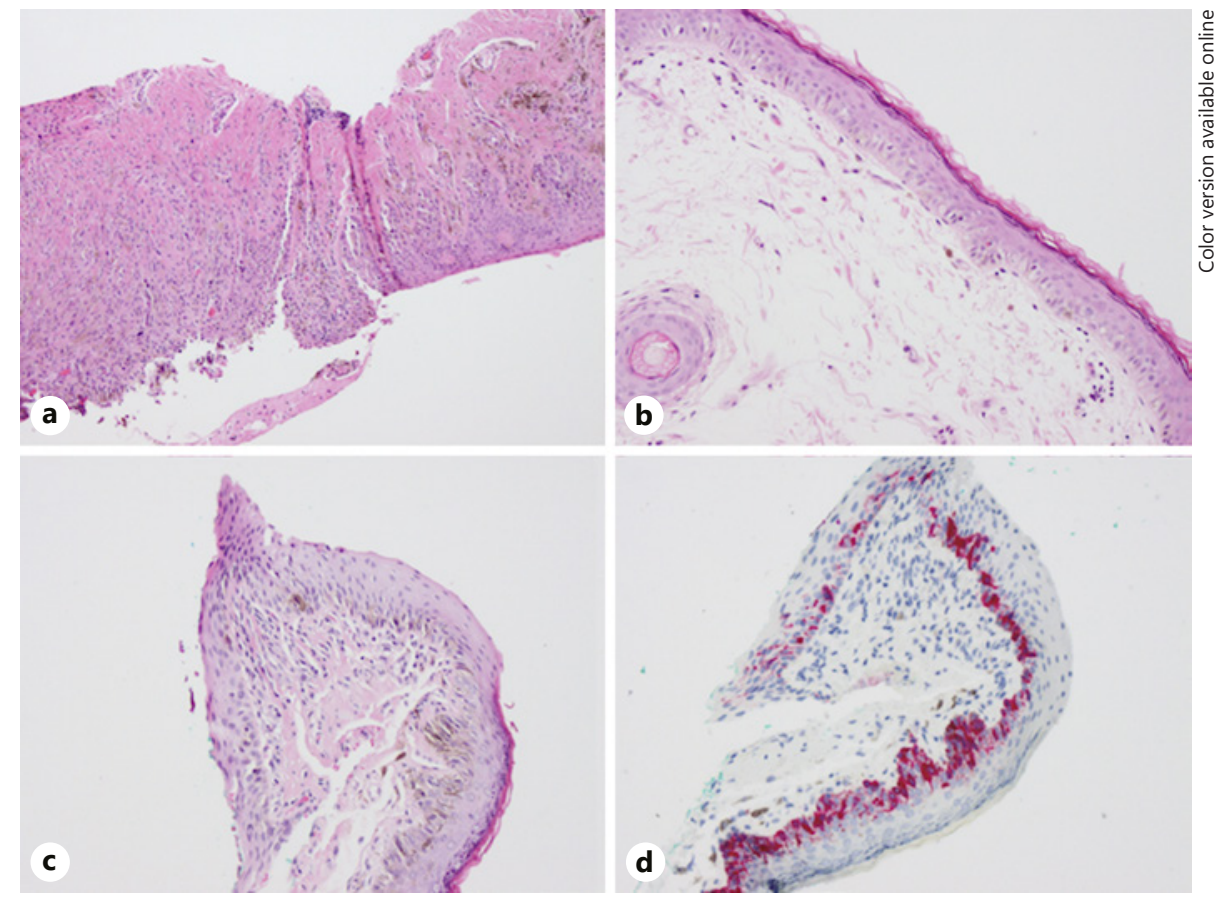

Table 1. Summary of previously reported cases of non-contiguous conjunctival and eyelid melanoma

\begin{tabular}{|c|c|c|c|c|c|}
\hline & $\begin{array}{l}\text { Cases } \\
\text { reported }\end{array}$ & Location & $\begin{array}{l}\text { Presence of } \\
\text { PAM }\end{array}$ & Treatment & $\begin{array}{l}\text { Local recurrence, metastasis and } \\
\text { survival }\end{array}$ \\
\hline $\begin{array}{l}\text { Giblin } \\
\text { et al. [17] }\end{array}$ & 2 & $\begin{array}{l}\text { CM: inferior bulbar } \\
\text { conjunctiva }(2) \\
\text { EM: upper eyelid }+ \\
\text { mucocutaneous jn (2) }\end{array}$ & $\begin{array}{l}\text { Yes [sine } \\
\text { pigmento] (1) } \\
\text { No PAM (1) }\end{array}$ & $\begin{array}{l}\text { CM: excision + cryotherapy } \\
\text { EM: full-thickness wedge resection }\end{array}$ & $\begin{array}{l}\text { No recurrence or metastasis at } \\
4 \text { years of follow-up }\end{array}$ \\
\hline $\begin{array}{l}\text { Hicks } \\
\text { et al. [19] }\end{array}$ & 1 & $\begin{array}{l}\text { CM: temporal bulbar } \\
\text { conjunctiva } \\
\text { EM: lower eyelid }+ \\
\text { mucocutaneous jn }\end{array}$ & Yes & $\begin{array}{l}\text { CM: excision + cryotherapy } \\
\text { EM: full-thickness wedge resection }\end{array}$ & $\begin{array}{l}\text { Recurrent conjunctival melanoma } \\
\text { at } 1 \text { year } \\
\text { No survival information reported }\end{array}$ \\
\hline $\begin{array}{l}\text { Jacinto } \\
\text { et al. [18] }\end{array}$ & 1 & $\begin{array}{l}\text { CM: superotemporal } \\
\text { bulbar conjunctiva } \\
\text { EM: lower eyelid }+ \\
\text { mucocutaneous jn }\end{array}$ & Yes & $\begin{array}{l}\text { CM: excision + cryotherapy } \\
\text { EM: full-thickness wedge resection }\end{array}$ & $\begin{array}{l}\text { Recurrent PAM } 1 \text { year following } \\
\text { surgery } \\
\text { No metastasis or cutaneous } \\
\text { recurrence at } 2 \text { years of follow-up }\end{array}$ \\
\hline $\begin{array}{l}\text { Rubinstein } \\
\text { et al. [20] }\end{array}$ & 1 & $\begin{array}{l}\text { CM: superior palpebral } \\
\text { conjunctiva } \\
\text { EM: upper eyelid + } \\
\text { mucocutaneous jn }\end{array}$ & Yes & $\begin{array}{l}\text { CM: excision + cryotherapy + } \\
\text { adjuvant MMC } \\
\text { EM: shave biopsy followed by } \\
\text { full-thickness wedge resection }\end{array}$ & $\begin{array}{l}\text { No recurrence or metastasis at } \\
2.5 \text { years of follow-up }\end{array}$ \\
\hline
\end{tabular}

$\mathrm{CM}$, conjunctival melanoma; EM, eyelid melanoma; jn, junction; MMC, mitomycin C.

sion, reconstruction with a mucous membrane graft and periosteal flap was performed.

In August 2017 an area of cutaneous pigmentation arising near the right lateral canthus was noted and consequently excised (Fig. 1a, 2d). Notably, there was no adjacent conjunctival pigmentation seen. Review of histopathology showed sun-damaged skin with a basal proliferation of atypical melanocytes in a lentiginous pattern. No nesting, pagetoid spread or evidence of invasive melanoma was seen. Resultantly, this area of pigmentation was felt to be consistent with lentigo maligna. At her most recent follow-up in July 2019, she was doing well with no evidence of local recurrence and no documentation of metastasis. 
A comprehensive review of the literature was performed by querying PubMed for the following key words: conjunctival melanoma, eyelid melanoma, conjunctival metastasis + cutaneous melanoma. This search yielded a total of 656 articles, 43 of which were included in this review.

\section{Discussion}

While conjunctival melanoma is a relatively rare malignancy, its incidence appears to be rising, particularly in white men [21]. Although contiguous eyelid pigmentation can be seen in up to $15 \%$ of patients [15], occurrence of ipsilateral EM is uncommon. Our patient initially presented with cT1a disease, given that there was $<1$ quadrant of bulbar conjunctival disease; however, this later became cT3b as the second lesion involved the eyelid. A review of the literature identified only 5 prior cases of non-contiguous CM and EM (Table 1).

\section{Eyelid Melanoma Preceding Conjunctival Melanoma}

There have been 3 cases of EM preceding ipsilateral CM. In 1988, Giblin et al. [17] reported 2 patients with upper eyelid melanoma involving the mucocutaneous junction who later went on to develop pigmented lesions of the inferior conjunctiva found to be CM. Similarly, Hicks et al. [19] reported a patient with lentigo maligna melanoma of the lower eyelid skin who later went on to develop ipsilateral CM arising on the bulbar conjunctiva. Proposed pathophysiological mechanisms underlying these presentations have included patchy involvement with PAM sine pigmento and dispersion of tumour cells, presumably through the tear film $[17,19]$.

\section{Cutaneous Melanoma Metastasis to the Conjunctiva Mimicking Primary CM}

Rarely, abnormal conjunctival pigmentation mimicking primary $\mathrm{CM}$ can occur in patients with a prior diagnosis of cutaneous melanoma. Reports documenting conjunctival metastasis have included patients with cutaneous melanoma arising at both distant (trunk [22, 23], axilla [24], scapula [25], vaginal mucosa [26]) and local (pre-auricular [27], temple [28], neck [29]) sites. Conversely, there have been rare reports of primary CM metastasizing to the eyebrow and cheek [30]; however, it is unclear whether or not the histopathological findings in these patients were consistent with in-transit metastasis or not.

In-transit metastasis occurs in up to $4 \%$ of cases of cutaneous melanoma and is a phenomenon attributed to in- tralymphatic spread resulting in a second lesion $>2 \mathrm{~cm}$ from the primary tumour but not beyond the regional nodal basin [31]. While conjunctival metastasis from $\mathrm{cu}-$ taneous melanoma typically occurs via haematogenous routes, Shields et al. [27] reported a very peculiar case of retrograde conjunctival metastasis via lymphatic channels of a cutaneous melanoma arising in the pre-auricular skin.

Recently Jacinto et al. [18] reported a case of presumably separate primary melanomas of the bulbar conjunctiva and eyelid skin in a patient previously treated for melanoma in situ arising in the forehead. As both the CM and EM arose within areas of intraepithelial neoplasia, the authors favoured the diagnosis of separate primaries over in-transit metastasis. Multiple primary melanomas occur in up to $2 \%$ of patients with cutaneous melanoma [32]; however, interestingly these patients do not appear to have a worse prognosis than their counterparts with single primary melanomas [33].

\section{Risk Factors for Local Recurrence of CM and EM}

Several clinical risk factors for recurrence of CM have been reported, including location not touching the limbus and involvement of margins on histopathology [4]. Histopathologically, tumour-associated lymphangiogenesis appears to increase the risk of local recurrence [34]. Risk factors for recurrence of EM include lower eyelid [8] or eyelid margin involvement [7] and incomplete excision [11].

Nearly one third of patients with CM develop another $\mathrm{CM}$ at a new conjunctival site due to the coexisting presence of PAM [13]. Rarely (3\%) patients who have been previously diagnosed with CM can develop a melanoma within the nasolacrimal system [35]. In a series of patients with advanced CM requiring exenteration, histopathological involvement of the lacrimal drainage apparatus was found in $29 \%$ despite only 1 case having clinically obvious disease pre-operatively [36]. The development of melanoma within the nasolacrimal system could represent a second primary melanoma arising from PAM of the nasolacrimal mucosa itself. Alternatively, atypical melanocytes have been found in the tear film of a patient with CM [37], and exfoliation of these cells may result in seeding of CM throughout the lacrimal drainage apparatus. Seeding of neoplastic melanocytes down the nasolacrimal duct is a significant risk during surgery which is why all excisions should be performed using a dry surgical field. While the incidence of lacrimal drainage apparatus involvement is certainly much lower when all cases of CM are taken into account, particularly those that are less advanced, Satchi et al. [36] recommended removal of 
the lacrimal sac and surrounding periosteum en bloc with the orbital contents in cases necessitating exenteration.

\section{Management of Advanced CM with Eyelid}

Involvement

Surgical excision using a no-touch technique, often with adjuvant cryotherapy to the conjunctival margins, remains the mainstay of initial management for CM. Sentinel lymph node biopsy appears to effectively identify nodal micrometastasis in patients with CM or EM, providing important prognostic information [38].

In an effort to avoid exenteration, Stannard et al. [39] reported a series of 14 patients with advanced or recurrent $\mathrm{CM}$ involving the eyelid or palpebral conjunctiva undergoing treatment with ${ }^{125}$ I plaque brachytherapy. Local control was achieved in the majority of cases (13/14) [39]. It is now widely accepted that adjuvant radiotherapy significantly improves local control of CM [40, 41]. In our case, adjuvant strontium-90 $\beta$-radiotherapy was used to successfully prevent local recurrence of the primary CM. We have reported a $90 \%$ local success rate using this radioactive source. More recently, checkpoint inhibition immunotherapy has shown some promise in patients with metastatic CM or advanced local disease involving the eyelid skin [42].

\section{Proposed Mechanisms of Ipsilateral CM and \\ Cutaneous EM}

The development of ipsilateral CM and EM may occur due to several possible mechanisms, including dispersion of malignant cells in the tear film, in-transit metastasis, direct local invasion (AJCC cT3b), separate primary melanomas or patchy involvement of PAM, which may be particularly challenging to identify whether it is sine pigmento. In our case, passive dispersion of melanoma cells in the tear film alone is an improbable explanation given that gravitational flow of the tears would be unlikely to result in superior eyelid involvement. However, it is certainly possible that the mechanical effect of the eyelid margin rubbing over the tumour several times per minute resulted in cellular liberation, with subsequent deposition along the mucocutaneous junction. Upon histopathological assessment, there was no evidence of spread along perivascular conduits or lymphatic involvement, both of which tend to be seen in cases of in-transit metastasis. Therefore, we feel that this explanation is equally implausible. Additionally, we are unaware of any well-documented cases of in-transit metastasis arising from CM.

Given that the cutaneous mapping biopsies showed a modest proliferation of atypical intraepithelial melano- cytes consistent with PAM, it is possible that the bulbar $\mathrm{CM}$ and EM represent separate primary lesions. However, as the lid margin was partially covered by flattened conjunctival epithelium showing features of melanosis with atypia, we favour patchy involvement with PAM and cutaneous overspill to be the most likely mechanism linking the two melanomas. In further support of this hypothesis, our patient later developed lateral canthal cutaneous pigmentation, found on histopathology to be consistent with lentigo maligna. As there was no clinically appreciable conjunctival pigmentation adjacent to this area, and all three pigmented lesions involved different quadrants of the ocular surface and adnexa, patchy PAM (which in some areas was likely sine pigmento) is the most logical mechanistic link.

\section{Conclusion}

$\mathrm{CM}$ can rarely involve the ipsilateral eyelid skin in a non-contiguous location. This case highlights the importance of long-term follow-up for patients diagnosed with $\mathrm{CM}$ as some instances of secondary eyelid involvement occur several years following the initial diagnosis. Our patient and 4 of the previously published cases had evidence of PAM which most likely serves as the underlying explanation for the non-contiguous eyelid involvement. Complex patients such as this are often best managed in a multidisciplinary setting, and at the present time, surgical excision of invasive melanoma remains the mainstay of treatment for both conjunctival and eyelid disease.

\section{Statement of Ethics}

This case report was prepared ethically in accordance with the World Medical Association Declaration of Helsinki. Written consent was obtained from the patient for permission of publication of the included images.

\section{Disclosure Statement}

None of the authors have any financial disclosures or conflicts of interest to declare.

\section{Author Contributions}

All authors participated in the conceptualization of the case report and review of the literature in addition to partaking in the construction, revision and approval of the final paper. 


\section{References}

1 Seregard S. Conjunctival melanoma. Surv Ophthalmol. 1998 Jan-Feb;42(4):321-50.

2 Chang AE, Karnell LH, Menck HR; The American College of Surgeons Commission on Cancer and the American Cancer Society. The National Cancer Data Base report on cutaneous and noncutaneous melanoma: a summary of 84,836 cases from the past decade. Cancer. 1998 Oct;83(8):1664-78.

3 De Potter P, Shields CL, Shields JA, Menduke $\mathrm{H}$. Clinical predictive factors for development of recurrence and metastasis in conjunctival melanoma: a review of 68 cases. Br J Ophthalmol. 1993 Oct;77(10):624-30.

4 Shields CL, Shields JA, Gündüz K, Cater J, Mercado GV, Gross N, et al. Conjunctival melanoma: risk factors for recurrence, exenteration, metastasis, and death in 150 consecutive patients. Arch Ophthalmol. 2000 Nov; 118(11):1497-507.

5 Shields CL, Markowitz JS, Belinsky I, et al. Conjunctival melanoma: outcomes based on tumor origin in 382 consecutive cases. Ophthalmology. 2011;118(2):389-95. e381-2.

6 Cook BE Jr, Bartley GB. Epidemiologic characteristics and clinical course of patients with malignant eyelid tumors in an incidence cohort in Olmsted County, Minnesota. Ophthalmology. 1999 Apr;106(4):746-50.

7 Tahery DP, Goldberg R, Moy RL. Malignant melanoma of the eyelid. A report of eight cases and a review of the literature. J Am Acad Dermatol. 1992 Jul;27(1):17-21.

8 Harish V, Bond JS, Scolyer RA, Haydu LE, Saw RP, Quinn MJ, et al. Margins of excision and prognostic factors for cutaneous eyelid melanomas. J Plast Reconstr Aesthet Surg. 2013 Aug;66(8):1066-73.

9 Grossniklaus HE, McLean IW. Cutaneous melanoma of the eyelid. Clinicopathologic features. Ophthalmology. 1991 Dec;98(12): 1867-73.

10 Mancera N, Smalley KS, Margo CE. Melanoma of the eyelid and periocular skin: histopathologic classification and molecular pathology. Surv Ophthalmol. 2019 May-Jun; 64(3):272-88.

11 Vaziri M, Buffam FV, Martinka M, Oryschak A, Dhaliwal H, White VA. Clinicopathologic features and behavior of cutaneous eyelid melanoma. Ophthalmology. 2002 May; 109(5):901-8.

12 Missotten GS, de Wolff-Rouendaal D, de Keizer RJ. Screening for conjunctival melanoma metastasis: literature review. Bull Soc Belge Ophtalmol. 2007;306:23-30.

13 Paridaens AD, Minassian DC, McCartney AC, Hungerford JL. Prognostic factors in primary malignant melanoma of the conjunctiva: a clinicopathological study of 256 cases. Br J Ophthalmol. 1994 Apr;78(4): 252-9.

14 Tas F, Erturk K. Palpebral cutaneous melanomas: a review of 17 cases from a tertiary center. Int J Dermatol. 2019 Jan;58(1):75-9.
15 Robertson DM, Hungerford JL, McCartney A. Pigmentation of the eyelid margin accompanying conjunctival melanoma. Am J Ophthalmol. 1989 Oct;108(4):435-9.

16 Collin JR, Allen LH, Garner A, Hungerford JL. Malignant melanoma of the eyelid and conjunctiva. Aust NZ J Ophthalmol. 1986 Feb;14(1):29-34.

17 Giblin ME, Shields JA, Shields CL, Eagle RC Jr. Primary eyelid malignant melanoma associated with primary conjunctival malignant melanoma. Aust NZ J Ophthalmol. 1988 May; 16(2):127-31.

18 Jacinto FA, Fisher GH, Espana EM, Leyngold IM, Margo CE. Separate Primary Melanomas of the Bulbar Conjunctiva and Eyelid Skin: Clinical Implications of Multiple Primary Melanomas. Ocul Oncol Pathol. 2016 Oct; 2(4):226-9.

19 Hicks C, Liu C, Hiranandani M, Garner A, Hungerford J. Conjunctival melanoma after excision of a lentigo maligna melanoma in the ipsilateral eyelid skin. Br J Ophthalmol. 1994 Apr;78(4):317-8.

20 Rubinstein TJ, Plesec TP, Singh AD. Desmoplastic melanoma of the eyelid and conjunctival melanoma in neurofibromatosis type 1: a clinical pathological correlation. Surv Ophthalmol. 2015 Jan-Feb;60(1):72-7.

$21 \mathrm{Yu}$ GP, Hu DN, McCormick S, Finger PT. Conjunctival melanoma: is it increasing in the United States? Am J Ophthalmol. 2003 Jun; 135(6):800-6.

22 Jakobiec FA, Buckman G, Zimmerman LE, La Piana FG, Levine MR, Ferry AP, et al. Metastatic melanoma within and to the conjunctiva. Ophthalmology. 1989 Jul;96(7):999-1005.

23 Kiratli H, Shields CL, Shields JA, DePotter P. Metastatic tumours to the conjunctiva: report of 10 cases. Br J Ophthalmol. 1996 Jan;80(1): 5-8.

24 Shields JA, Shields CL, Eagle RC Jr, Raber IM. Conjunctival metastasis as initial sign of disseminated cutaneous melanoma. Ophthalmology. 2004 Oct;111(10):1933-4.

25 Brouwer NJ, Marinkovic M, Jochems A, Kapiteijn EW, van Duinen SG, Haeseker BI, et al. Conjunctival Metastasis of a Cutaneous Melanoma. Ocul Oncol Pathol. 2018 Sep;4(2): 107-11.

26 Phelps PO, Farber MJ, Meyer DR. Pigmented Conjunctival Lesions as Presenting Signs of Vaginal Melanoma. Ocul Oncol Pathol. 2018 Sep;4(2):79-81

27 Shields JA, Eagle RC Jr, Gausas RE, Bundy WE 3rd, Shields CL. Retrograde metastasis of cutaneous melanoma to conjunctival lymphatics. Arch Ophthalmol. 2009 Sep;127(9): 1222-4.

28 Carey AR, Espana EM, Margo CE. Conjunctival metastasis from a regional cutaneous melanoma. Can J Ophthalmol. 2014 Aug; 49(4):e97-9.

29 Kwapiszeski BR, Savitt ML. Conjunctival metastasis from a cutaneous melanoma as the initial sign of dissemination. Am J Ophthalmol. 1997 Feb;123(2):266-8.

30 Bianciotto C, Demirci H, Shields CL, Eagle RC Jr, Shields JA. Metastatic tumors to the eyelid: report of 20 cases and review of the literature. Arch Ophthalmol. 2009 Aug;127(8): 999-1005.

31 Knackstedt T, Knackstedt RW, Couto R, Gastman B. Malignant Melanoma: Diagnostic and Management Update. Plast Reconstr Surg. 2018 Aug;142(2):202e-16e.

32 Moore MM, Geller AC, Warton EM, Schwalbe J, Asgari MM. Multiple primary melanomas among 16,570 patients with melanoma diagnosed at Kaiser Permanente Northern California, 1996 to 2011. J Am Acad Dermatol. 2015 Oct;73(4):630-6.

33 Kricker A, Armstrong BK, Goumas C, Thomas NE, From L, Busam K, et al.; GEM Study Group. Survival for patients with single and multiple primary melanomas: the genes, environment, and melanoma study. JAMA Dermatol. 2013 Aug;149(8):921-7.

34 Heindl LM, Hofmann-Rummelt C, Adler W, Bosch JJ, Holbach LM, Naumann GO, et al. Prognostic significance of tumor-associated lymphangiogenesis in malignant melanomas of the conjunctiva. Ophthalmology. 2011 Dec;118(12):2351-60

35 Missotten GS, Gambrelle J, de WolffRouendaal D, de Keizer RJ. Epistaxis or epiphora as a sign for extension of a conjunctival melanoma. A series of six patients with nasolacrimal recurrence. Br J Ophthalmol. 2010 Oct;94(10):1328-31.

36 Satchi K, McKelvie P, McNab AA. Malignant melanoma of the lacrimal drainage apparatus complicating conjunctival melanoma. Ophthal Plast Reconstr Surg. 2015 May-Jun;31(3): 207-10.

37 Weiss JS, Perusse P, Reale F. Tear cytology in conjunctival melanoma. Am J Ophthalmol. 1991 May;111(5):648-9.

38 Savar A, Ross MI, Prieto VG, Ivan D, Kim S, Esmaeli B. Sentinel lymph node biopsy for ocular adnexal melanoma: experience in 30 patients. Ophthalmology. 2009 Nov;116(11): 2217-23.

39 Stannard CE, Sealy GR, Hering ER, Pereira SB, Knowles R, Hill JC. Malignant melanoma of the eyelid and palpebral conjunctiva treated with iodine-125 brachytherapy. Ophthalmology. 2000 May;107(5):951-8.

40 Cohen VM, Papastefanou VP, Liu S, Stoker I, Hungerford JL. The use of strontium-90 beta radiotherapy as adjuvant treatment for conjunctival melanoma. J Oncol. 2013;2013:349162.

41 Damato B, Coupland SE. An audit of conjunctival melanoma treatment in Liverpool. Eye (Lond). 2009 Apr;23(4):801-9.

42 Finger PT, Pavlick AC. Checkpoint inhibition immunotherapy for advanced local and systemic conjunctival melanoma: a clinical case series. J Immunother Cancer. 2019 Mar;7(1): 83. 